\title{
Do Emotions, Nature Relatedness, and Conservation Concern Influence Students' Evaluations of Arguments about Biodiversity Conservation?
}

\author{
Iresha Jayasinghe ${ }^{1}$, Rebekka Darner ${ }^{2 \star}$
}

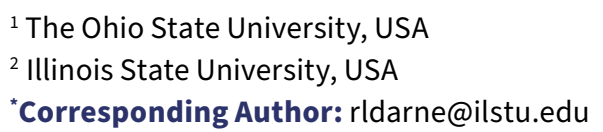

Citation: Jayasinghe, I., \& Darner, R. (2021). Do emotions, nature relatedness, and conservation concern influence students' evaluations of arguments about biodiversity conservation? Interdisciplinary Journal of Environmental and Science Education, 17(1), e2230. https://doi.org/ 10.29333/ ijese/9157

\section{ARTICLE INFO ABSTRACT}

Received:

31 July 2020

Understanding human treatment towards nature provides insight into mitigating human induced

Accepted:

15 October 2020 environmental issues. This study determines whether individuals' relationships with nature (NR), emotions experienced during evidence evaluation, and conservation concern drive evaluation of scientific arguments made about biodiversity conservation. Although we predicted that participants with strong NR would exhibit motivated reasoning, resulting in strong argument-evaluation skills as they evaluate an anti-conservation argument, we found that participants' emotions during evidence evaluation were more predictive of their argument-evaluation skills. Further, participants with either low or high conservation concern demonstrated better argumentation skills. These findings suggest that while fostering strong relationships with nature may be important, of greater importance is to address emotions experienced when evaluating evidence. Furthermore, this study indicates a possibility that one's reasoning about arguments made about biodiversity conservation may be motivated by how important one deems conservation to be.

Keywords: conservation education, nature relatedness, emotion, scientific argumentation, motivated reasoning

\section{INTRODUCTION}

"Cherish the natural world because you are a part of it, and you depend on it."

David Attenborough

Environmental problems such as global warming, habitat destruction, and pollution have become topics of discussion around the world, making it evident that human activities play a major role in degrading nature. It is important to examine humans' relationship with nature and their reasoning about biodiversity conservation to better understand the reasons why the environment is thus being treated. Such understanding provides directions for solutions to mitigate these problems. As an initiative to address this concern, Nisbet, Zelenski, and Murphy (2009) developed the Nature Relatedness (NR) Scale. It was proposed to describe individuals' levels of connectedness to the natural world and encompasses appreciation for and understanding of our interconnectedness with all other living things on Earth. NR assesses the affective, cognitive, and experiential aspects of individuals' connections to nature (Nisbet et al., 2009). It also predicts love for animals, membership in environmental organizations, self-identification as an environmentalist, preference for "green" products, and several indicators of well-being (Tam, 2013).

Scientific argumentation is a logical and rational discourse aimed at finding relationships between claims and evidence (Duschl, Schweingruber \& Shouse, 2007). Thus, it plays a central role in the development, evaluation, and validation of scientific knowledge and is considered an important practice in distinguishing science from other ways of knowing (Driver, Newton, \& Osborne, 2000; Duschl \& Osborne, 2002). Conceptual change, is the construction of mental representations of concepts and their interconnections, resulting in the evolution of 
a learner's knowledge, conceivably, toward knowledge that is consistent with scientific consensus (Chi, 2008). Students who engage in argumentation with their peers experience enhanced conceptual development, similar to scientists (Asterhan \& Schwarz, 2009). Uncertainty in science arises from errors, including observational, material, conceptual and discursive errors (Allchin, 2012). When scientists or students investigate the source of errors in more detail scientific or students' knowledge can change (Lee et al., 2014). Scientific argumentation provides students opportunities to explore sources of their uncertainty by questioning limitations in the design or phenomena under investigation. This paves the way for conceptual change to occur, compelling the students to engage in higher levels of argumentation and allowing the evolution of student knowledge. The Uncertainty-Infused Scientific Argumentation Test (USAT) assesses scientific argumentation across science topics and disciplines and allows students to engage in argumentations across levels of uncertainty (Lee et al., 2014).

When addressing humans' deleterious actions toward nature, understanding how humans interpret environmental problems allows scientists, environmentalists, and educators to devise approaches for solutions. This study begins exploration of whether individuals evaluate environmental issues using their emotions, concern about the issue, and/or evidence. Additionally, we examine argumentation skills as they vary with one's connection with nature, which will allow educators to address learners appropriately to how they perceive nature. When someone has an emotional attachment to nature, what does their evaluation of scientific arguments look like? And conversely, when someone has a weak relationship with nature, what might their evaluation of scientific arguments about conservation look like? Answers to these research questions will help environmental educators understand how scientific arguments are interpreted and evaluated differently, according to one's relationship with nature.

\section{LITERATURE REVIEW}

\section{The Human-Nature Relationship}

"Disconnection from the natural world may be contributing to our planet's destruction" (Nisbet et al., 2009, p. 715). Thus, ways of reconnecting humans to nature has become a point of interest to many environmental psychologists and environmental education researchers. The development of several psychological constructs and instruments has played an important role mitigating environmental issues, using the notion of connection to nature. These instruments focus on identifying cognitive and emotional aspects of the relationship between humans and nature, as well as the knowledge that affects the human-nature relationship.

The Nature Relatedness scale (NR) created by Nisbet, Zelensky and Murphy (2009) addresses multiple dimensions on the subject. This study will examine the human-nature relationship using the construct of nature relatedness measured by the NR Scale which assesses the affective, cognitive, and experiential aspects of an individual's connection to nature. This is a concept that identifies one's appreciation for and understanding of the interconnectedness with all living things on Earth. "Distinct from environmentalism, it is not simply a love for nature for just the pleasing facets of nature but also the aspects that are not so aesthetically appealing" (Nisbet et al., 2009, p. 718). The NR Scale captures all components (cognitive, emotional and physical) involved in the humannature relationship. The full-length NR Scale includes 21 items and was found to be too lengthy for some research purposes. Thus, Nisbet and Zelenski (2013) developed a shorter version of the scale consisting of 6 items. The modified scale retained good psychometric properties (Nisbet \& Zelenski, 2013) and is useful in research contexts where time or space is limited (Nisbet \& Zelenski, 2013).

Nisbet et al. (2009) suggests that alongside the interest of learning how to increase and motivate proenvironmental behavior, a more in-depth investigation of the underlying contributions to environmental concern and caring is necessary. They argue that NR, which includes emotions, values, attitudes, and self-concept related to the natural world, provides a motivational force toward the protection and preservation of nature. According to Kaplan (2000), motivating humans to engage in environmentally responsible activities is not effective if they are simply told what to do. He suggests that enriching human desire, by giving opportunities to increase understanding and participation, will be more successful in engaging humans in more responsible behavior towards nature.

Although multiple scales are used in exploring the human relationship with nature, this study uses the NR scale because 1) it has a high internal validity across multiple studies 2) it is a strong predictor of several variables that might be relevant to scientific argumentation and 3) it has a strong relationship to environmental behavior, conservation, and self-reported ecological behavior (Tam, 2013).

\section{Humans' Conservation Concern for Biodiversity}

Several studies have demonstrated the variable preferencesofhumanstowardstheconservationofspecies. Understanding human preferences towards groups of species is important in implementing conservation 
efforts (Batt, 2009). Kellert (1978) showed that variable preference for species occurs due to: 1 . An individual's prior attitude towards, and values of, wildlife and nature 2. An individual's previous experience and knowledge of a species or group. 3. The relationship between species and humans, for example cultural significance, utility value or conservation status. 4. Human perceptions of individual species (in terms of aesthetic value, assumed intelligence, threat, etc.). Czech et al. (1998) stated that birds and mammals were favored for conservation over reptiles and invertebrates. Other studies also show that people also seem to prefer conserving animals that are like humans (DeKay \& McClelland, 1996). These studies show that the success of conservation efforts for many species also depend on human attitudes towards species groups, which demonstrates the importance of human perceptions to be considered when implementing argumentation tasks related to biodiversity conservation. In this study, we ask participants to consider conservation of birds and mammals. These two species groups were selected because both birds and mammals are considered charismatic species, receiving more attention from humans than fish, reptiles, amphibians and invertebrates (Colléony et al. 2017).

\section{Scientific Argumentation}

Scientific argumentation bridges a claim with pieces of evidence, allowing conceptual development and scientific thinking in students. It can be defined as a complex cognition that requires scientific reasoning to coordinate theory and evidence, coupled with critical thinking about the strength of an argument (Lee et al., 2014). Most educational research focuses on the scientific reasoning to coordinate theory and evidence, with less emphasis on the critical reasoning required to evaluate the strength of an argument, which also includes considering uncertainty (Duschl \& Osborne, 2002). Thus, this study utilizes Toulmin's (1958) taxonomy of argumentation, which attends to uncertainty during argumentation. Toulmin's framework is widely used in investigations of argumentation.

Lee et al. (2014), also takes Toulmin's approach to assess argumentation skills of students. Addressing the gap of importance of critical reasoning in evaluating the strength of an argument, they introduced a framework which considers both scientific and critical reasoning in scientific argumentation. They argue that a scientific argumentation may include a claim, justification of the claim, an uncertainty qualifier, and an uncertainty rationale. They have adopted Toulmin's concept into a framework with six levels of argumentation on increasing levels of sophistication. Level 0 shows non-scientific statements. At level 1, students make a scientific claim without supporting evidence or relevant knowledge. At level 2, a claim is made by students that is based on important data or relevant knowledge but without explicit connection between the two. At level 3, the claim they make is based on coordination between important evidence and relevant knowledge or theories. At level 4 , the strength of the argumentation is tempered by acknowledging a degree of uncertainty in the claim. At level 5 , the students can distinguish conditions where their scientific argumentations are held true and recognize limitations with measurements, current knowledge base/ model, and phenomena. Their assessment framework provides means to assess and document the development of students' understanding of scientific argumentation elements across scientific topics through time.

\section{Emotion's Influence on Argumentation}

For most people, goals, such as evaluating information, are emotionally meaningful. Garcia-Marques and Loureiro (2016) demonstrated that emotions play a part in evidence evaluation. Similarly, Albarracin and Kumkale (2003) found that, "if individuals believe that their feelings are a sound basis for judgment, they use them in forming their attitudes; [conversely,] if they believe that these feelings are irrelevant, they exclude them from consideration" (p. 453). Also, emotions can affect goal-pursuits and cognitive control (Chiew \& Braver, 2011). Thus, it is important to examine whether argumentation is influenced by emotions, which is why, when examining at individuals' scientific argumentation, we consider how emotions affect argumentation skills.

\section{Socio-Scientific Issues}

Being able to make informed decisions connected to socio-scientificissues promotesconceptualunderstanding and engagement in rational argumentation (Lee, 2007). Decisions made about socio-scientific issues include personal and social dimensions connecting science with everyday decisions. Millar and Osborne (1998), advocate giving students assistance in understanding the conceptual and procedural components of science that will allow them to comprehend and respond critically to science-related media. Thus, formulation of theoretical models and pedagogic practices to enhance student ability in making informed decisions in relation to socioscientific issues has become important among education researchers (Lee, 2007). Socio-scientific issue-based (SSI-based) education has been considered an effective way to support science learning while developing science literacy (Presley et al., 2013). By using SSIs, the students learn to build an interrelationship between social, 
political, and scientific perspectives, which in turn let them participate in practices such as argumentation, reasoning, and decision-making (Presley et al., 2013). This study, which is considering students' decision-making in relation to biodiversity conservation, will give insight into how students can be engaged in scientific argumentation within an environmental context.

\section{Motivated Reasoning}

Reasoning about evidence is affected by one's motivation to believe its conclusion (Kunda, 1990). "Subjects motivated to disbelieve the evidence are less likely to believe it, and there is some evidence that this outcome is mediated by differential processing of the information" (Kunda, 1990, p. 489). For example, in a study by Wyer and Fray (1983), they gave research participants success and failure feedback on an intelligence test and then later exposed them to a report that contained favorable and unfavorable information about intelligence tests. Subjects receiving failure feedback judged intelligence tests to be less valid than the subjects receiving positive feedback. Similarly, Kunda (1987) had respondents read an article that claimed caffeine is risky for women. Women who heavily consumed caffeine were less convinced by this article than the women who consumed less caffeine, demonstrating that only the women who might experience unflattering judgment of their caffeine consumption doubted the article's truth.

Such studies reflect the concept of motivated reasoning, which is when evaluation of scientific evidence is biased by whether people want to believe the conclusions (Kunda, 1990). "Most people are not at a liberty to believe what they want but are constrained by their prior beliefs" (Kunda, 1990, p. 489). Connecting the concept of motivated reasoning to this research, students' argumentation skills related to conservation issues might be motivated by their relationship to nature. If participants with a strong relationship with nature are confronted with anti-conservation claim, they may evaluate the argumentation the claim is built upon more negatively than would individuals with a weaker relationship with nature. If there is such a difference, it may indicate that evaluation of scientific arguments about environmental issues is subject to motivated reasoning, such that one's relationship with nature, not only by the evidence provided, influences one's conclusion. Similarly, if participants with a strong relationship with nature are presented with a pro-conservation claim, they may evaluate the argument more positively than individuals with a weak relationship with nature. Argument evaluation may be motivated by one's relationship to nature. If there is no such difference, then it can be concluded that their evaluation of the argument is not motivated by their relationship with nature.

\section{THEORETICAL PERSPECTIVE}

Our theoretical perspective for this study draws upon these reviewed literatures. Individuals' relationships with nature, emotion's influence on scientific argumentation, conservation concern for species as well as aspects of scientific argumentation have been addressed by many authors. We assume Lee et al.'s (2014) extension of Toulmin's (1958) taxonomy of scientific argumentation as the framework through which we operationalize argumentation. While hypothesizing the multiple potential influences on argumentation, we frame the consequences these influences through the theory of motivated reasoning (Kunda, 1990), acknowledging that one's reasoning about evidence related to biodiversity conservation, may be skewed by their relationship to nature or concern for conservation, leading them to be less concerned with coming to an accurate conclusion according to the data, and more likely to manipulate the evidence evaluation to arise at the conclusion that aligns with their nature relatedness or conservation concern. Thus, in this time of globalupheaval, when scientificliteracy is both threatened and necessary to protect our collective well-being, we marry the scientific argumentation (Lee et al., 2014; Toulmin, 1958) and motivated reasoning (Kunda, 1990) theoretical frameworks to understand how argument evaluation occurs when people feel passionate about the socio-scientific issue at hand. In doing so, we contribute a new exploration of scientific argumentation and bridges several literatures together, for the purpose of yielding a novel approach to addressing environmental and biodiversity issues.

\section{RATIONALE \& HYPOTHESES}

Scientific argumentation about biodiversity conservation issues can be based on multiple variables: one's relationship to nature, the emotions experienced during argumentation, motivated reasoning, as well as emotions felt about the importance of conservation of biodiversity. It is important to comprehend the effects from all these variables in the formulation of higher levels of argumentation skills and to identify which play significant roles in influencing argumentation evaluation skills. In this study, we begin by measuring participants' nature relatedness and concern for conservation of species. Then we ask participants to evaluate two claims related to biodiversity conservation, both of which are said to be backed up by evidence. We follow up by asking about their emotions experienced during evidence 
evaluation. By observing participants' evaluation of the arguments, we seek to elucidate influences on scientific argumentation skills, namely the skills involved in evaluating claims purported to be evidence-based, particularly when evaluating claims about biodiversity conservation.

We hypothesized that participants would exhibit motivated reasoning during evaluation of arguments related to biodiversity conservation, due to influence of their relationship to nature and concern for biodiversity conservation. We also hypothesized that emotions experienced during evaluation of arguments would influence argument evaluation skills. Specifically, it was predicted that participants with a strong relationship with nature or high concern for conservation would exhibit high quality argument evaluation skills as they evaluated an anti-conservation argument, while participants with a weak relationshiptonature or low concern for conservation would exhibit high quality argument evaluation skills as they evaluated a pro-conservation argument. We also predicted that participants who experienced positive emotions during evidence evaluation would demonstrate higher quality argument evaluation skills, compared to participants who experienced negative emotions during evidence evaluation.

\section{METHODS}

\section{Participants}

Participants for this research were 236 undergraduate students from a large Midwestern university in the United States. They were recruited via email by using the university mass email listserv. The email included a cover letter with a link to Qualtrics, through which the questionnaire was administered in the spring of 2019.

\section{Data Collection}

The questionnaire designed for this study had three main components: 1) Items measuring participants' evaluation of scientific arguments, 2) The 6-item NR scale, 3) Demographic questions that ask about major, year of birth, race and ethnicity, gender, details on their hometown (e.g., rural vs. urban), and whether they voted in the last election.

Relationship to nature was measured using the short version of the NR scale (Nisbet \& Zelenski, 2013), which consists of six statements on which participants rate degree of agreement using a 5-point Likert scale ranging from 1 (disagree strongly) to 5 (agree strongly) (Nisbet et al., 2009).

Scientific argumentation skills were measured using a version of the USAT (Lee et al., 2014), modified to focus solely on argumentation about biodiversity conservation
(Supplement A). The USAT (Lee et al., 2014) was based on Toulmin's (1958) taxonomy of argumentation and allows identification of six levels (0-5) of scientific argumentation skills among students, on a continuum toward increasing sophistication (Lee et al., 2014; Table 1). Level 0 represents non-scientific statements. At level 1, the scientific claim is made without supporting evidence or relevant knowledge. At level 2, a claim is based on important data or relevant knowledge but without explicit connection between the data and the claim. At level 3, the claim is supported by coordination between evidence and relevant knowledge or theories. At level 4, the strength of the argumentation is tempered by acknowledgment of a degree of uncertainty in the claim. At level 5, there is a distinction between conditions where their scientific arguments are held true and when they are not and a recognition of limitations with measurements, current knowledge base or model, and phenomena.

The portion of the survey measuring participants' evaluation of scientific arguments began with an item that asked participants to rank (0-10) the importance of conservation of primates, carnivores, and birds. Then participants were posed two scenarios addressing biodiversity conservation, specifically conservation of these groups of organisms. Qualtrics was programmed to assign the two argumentation tasks randomly, such that each participant received both items but in a random order. Each scenario included a data table, a photo representing the taxon discussed in the scenario, and text of the prompt. Both scenarios presented to participants authentic, published data focusing on the conservation of primates, carnivores, and birds. Each scenario stated that one of two characters, Jordan or Jaime, makes a claim that is said to be based upon the data provided. Jaime puts forth a pro-conservation claim that supports biodiversity conservation that Jaime claims is based on the data provided in the scenario. Jordan puts forth an anti-conservation claim that is not in favor of biodiversity conservation that Jordan claims is based on the data provided in that scenario. Participants were asked to evaluate the validity of the claim, based on their own evaluation of the data. The data included percentages of species populations sizes, species distributions, and population sizes; in both scenarios, the mathematical concepts included percentages and relative population size, thus both requiring proportional reasoning but no mathematical calculations. We chose gender neutral names to reduce influence of participants' biases about which gender is more capable of data evaluation. Participants' responses allowed for identification of the level of argumentation evaluation, according to Lee et al.'s (2014) levels (Table 1). 
Table 1. Construct map, modified from Lee et al. (2014), for scientific argumentation involving claim, justification, uncertainty rating, and uncertainty rationale, corresponding to levels 0-5 argumentation. Examples of each argumentation score from this study are provided

\begin{tabular}{|c|c|c|c|}
\hline Description of the level & Toulmin (1958) & Response Characteristics & $\begin{array}{l}\text { Exemplar from this Study (Scenario 1: } \\
\text { Evaluation of anti-conservation claim) }\end{array}$ \\
\hline
\end{tabular}

Level 0: Non-Scientific

Level 1: Scientific Claim Claim

Level 2: Coordination between claim and evidence

Level 3: Reasoned coordination between claim and evidence

Claim + data

Claim + data + warrant/backing

Claim + data + warrant/backing + qualifier

Claim + data + warrant/backing + qualifier + conditions of rebuttal
Level 4: Modified, reasoned coordination between claim and evidence

Level 5: Conditional, modified, reasoned coordination between claim and evidence
Students think scientific claims can be made without support of evidence

Students recognize that adequate evidence is needed to support a claim

Students can use theory or established knowledge to coordinate claim and evidence

Students recognize the uncertainty of claim given the strength of warrants

I love these animals

Jordan is wrong

I disagree because for most of the animals, a percentage higher than $80 \%$ was traded which is a big percentage I disagree because for most of the animals a high percentage of the wild population is traded and if this continues these species will become extinct in the wild

It could be correct if these animals continued to reproduce but based on the percentage that is traded that seems unlikely

Students recognize conditions that the current claim may not be held by analyzing limitations related to measurements, current theory/model, and phenomena under investigation
The claim purported to be based on the presented data was followed by an item asking for the participants' degree of agreement (strongly agree to strongly disagree) with Jaime/Jordan. Then, in a close-ended question, participants were asked to identify why they agreed or disagreed; response choices corresponded to argumentation levels $0-3$. Response choices were ordered randomly. Next, an open-ended question asked participants to explain why they agreed or disagreed with Jaime/Jordan. Written responses were coded by both authors to identify Level 4 or 5 argumentation. Level 4 demonstrated a participant's recognition of the uncertainty of Jordan/Jaime's claim, given the strength of the warrants, while Level 5, the highest level of argumentation, demonstrated a participant's recognition of conditions that the claim may not be true by analyzing limitations related to measurement or the phenomenon under investigation.

Immediately following each scientific argumentation scenario, participants were asked to self-report their subjective experience by ranking the degree to which they experienced 6 emotions (i.e., angry, sad, frustrated, happy, satisfied, pleased) during the evidence evaluation, on a scale from -10 to +10 , where negative values indicated negative emotions and positive values indicated positive emotions experienced during evidence evaluation. Mauss and Robinson (2009) have stated that "self-reports of emotion are likely to be more valid to the extent that they relate to currently experienced emotions" (p. 211). Given that participants were asked to self-report on their emotion directly following the evidence evaluation, we argue this method to be an acceptable measure of emotions experienced during the evidence evaluation.

\section{Data Analysis}

The responses of the NR scale ranged from 1-5. Scores for all six items for each respondent were averaged to capture their nature relatedness (Nisbet et al., 2009).

Coding of the open-ended questions were carried out by two coders (authors). Percent agreement between the 
Table 2. Scenario 1 descriptive statistics for argument evaluation skills (AS), nature relatedness (NR), emotion experienced during evidence evaluation (EE), and conservation importance (CI)

\begin{tabular}{lll}
\hline Variable & Mean & SD \\
\hline AS & 2.58 & 0.98 \\
NR & 3.50 & 0.74 \\
ES & -4.07 & 4.10 \\
Cl & 3.64 & 3.43 \\
\hline
\end{tabular}

Table 3. The summary statistics of regression coefficients for bootstrapped regression $\left(\mathrm{N}_{\mathrm{s}}=3000\right)$ for scenario 1

\begin{tabular}{llllll}
\hline Variable & Estimate Mean & SE & Bias & $p$-value & $95 \% \mathrm{Cl}$ \\
\hline Constant & 2.54 & 0.28 & -0.01 & $<0.01$ & {$[2.02,3.07]$} \\
NR & -0.06 & 0.08 & 0.00 & 0.42 & {$[-0.23,0.10]$} \\
EE & -0.06 & 0.01 & 0.00 & $<0.01$ & {$[-0.09,-0.04]$} \\
\hline
\end{tabular}

Table 4. Scenario 2 descriptive statistics for argument evaluation skills (AS), nature relatedness (NR), emotion experienced during evidence evaluation (EE), and conservation importance (Cl)

\begin{tabular}{lll}
\hline Variable & Mean & SD \\
\hline AS & 2.71 & 1.05 \\
NR & 3.50 & 0.74 \\
EE & 2.15 & 5.54 \\
$\mathrm{Cl}$ & 3.64 & 3.43 \\
\hline
\end{tabular}

two coders was initially $70.0 \%$ for scenario 1 and $67.2 \%$ for scenario 2. Disagreements were resolved through discussion to reach a consensus.

The curve estimation function in SPSS version 26 revealed that conservation concern had a nonlinear relationship with argumentation skills in both scenarios and thus was removed from the multiple regression model. A separate regression analysis was carried out to elucidate conservation concern predicting argumentation scores. Then, to elucidate which independent variables predicted argumentation evaluation skills, separate multiple regression analyses with bootstrapping $\left(\mathrm{N}_{\mathrm{s}}=3000\right)$ were performed for each scenario, using emotion and nature relatedness to predict argumentation evaluation skills. Bootstrapping was utilized due to violation of the normality of errors assumption. Confidence intervals were estimated using the bias corrected accelerated method.

\section{RESULTS}

\section{Participant Demographics}

A majority of the participants were sophomores (67.79\%), identified themselves as White/European American (86\%), and did not identify as Spanish/Hispanic/ Latino (90.25\%). A majority of participants identified as female (69.06\%), and aboutquarter of themwere education majors (23.72\%), closely followed by business majors (23.3\%). More than half of the participants described their hometown as suburban (59.74\%, Supplement B).

Scenario 1: Evaluation of an Anti-Conservation Claim. In the scenario in which participants were asked to evaluate an anti-conservation claim, mean argumentation evaluation skills were $2.58 \pm 0.98$, and mean emotion scores were $-4.07 \pm 4.10$ (Table 2). The bootstrapped multiple regression analysis $\left(\mathrm{N}_{\mathrm{s}}=3000\right)$ using emotion and nature relatedness to predict argument evaluation skills revealed a significant effect of emotion experienced during evidence evaluation; with every 1-point change in emotion, there was a -0.06 change in argument evaluation skills. NR did not have a significant effect on argumentation evaluation skills (Table 3).

The nonlinear regression analysis in which conservation concern was used to predicted argumentation skills revealed a marginally significant $\left(R^{2}=0.02 ; d f=2,2330 ; p\right.$ $=0.10)$ quadratic relationship $\left(y=2.78-0.126 x+0.010 x^{2}\right)$, such that higher argumentation levels were observed when students had low or high conservation concern.

Scenario 2: Evaluation of a Pro-Conservation Claim. In the scenario in which participants were asked to evaluate a pro-conservation claim, mean argumentation evaluation skills were $2.71 \pm 1.05$, and mean emotion scores were $2.15 \pm 5.54$ (Table 4). In the multiple regression analysis with bootstrapping $\left(\mathrm{N}_{\mathrm{s}}=3000\right)$ using emotion and 
Table 5. The summary statistics of regression coefficients for bootstrapped regression $\left(\mathrm{N}_{\mathrm{s}}=3000\right)$ for scenario 2

\begin{tabular}{llllll}
\hline Variable & Estimate Mean & SE & Bias & p-value & $95 \% \mathrm{Cl}$ \\
\hline Constant & 2.59 & 0.31 & 0.00 & 0.00 & {$[1.93,3.2]$} \\
NR & 0.03 & 0.88 & 0.00 & 0.71 & {$[-0.14,0.19]$} \\
EE & 0.01 & 0.01 & 0.00 & 0.57 & {$[-0.017,0.03]$} \\
\hline
\end{tabular}

nature relatedness to predict argumentation skills, no significant predictors for scientific argumentation were identified (Table 5).

\section{DISCUSSION}

In this study, we hypothesized that participants would exhibit motivated reasoning during evaluation of arguments related to biodiversity conservation, due to influence of their relationship to nature and their conservation concern. We also hypothesized that participants who experienced positive emotions during evaluation of arguments would exhibit stronger argumentation skills. However, NR had no statistically significant influence on the levels of scientific argumentation in either scenario. This non-significant result between NR and scientific argumentation scores regarding biodiversity conservation issues indicates that having a strong relationship to nature does not seem to foster motivated reasoning when evaluating scientific arguments, regardless of whether the claim being made is in favor or in opposition to biodiversity conservation. These results make sense in light of a recent study conducted by Wang et. al (2020) in which they sought to understand the relationships among adults' sustainability attitudes, psychological well-being, nature relatedness, and interest in scientific issues. This study revealed that adult interest in scientific issues had a direct effect on adult nature relatedness, which, in turn, had direct effects on sustainability attitudes and psychological wellbeing. Given Wang et al.'s (2020) findings, it makes sense that people with strong nature-relatedness do not exhibit motivated reasoning during evidence evaluation. In this research, accuracy-oriented reasoning may have played a role on participant's reasoning skills. Kunda (1990) explains that accuracy-driven reasoning is a reasoning driven by accuracy goals when people are motivated to be accurate. People tend to process information related to issue-related reasoning more deeply by spending more cognitive effort. The data-heavy nature of our questionnaire might have prompted some degree of accuracy-oriented reasoning among our participants with a strong interest in scientific issues co-occurring with a strong relationship to nature, which could have resulted in the absence of motivated reasoning that we observed.

\section{Emotion and Scientific Argumentation}

In evaluating the anti-conservation claim, it was found out that the emotions experienced during argument evaluation had a significant effect on argumentation evaluation skills; as emotions became more positive, participants' skills in argument evaluation diminished. This was only observed in the scenario in which participants were asked to evaluate an anti-conservation claim, so it is plausible that simply hearing an anticonservation claim elicited negative emotions. Indeed, Villata et al. (2017) found that conflicting opinions during debate elicit negative emotions. Further, these negative emotions seemed to have compelled participants to evaluate the claim with more skepticism.

Given that emotion experienced during evidence evaluation was the strongest predictor of argument evaluation skills, we consider the possibility that mathematics anxiety might be at play. Initially described as mathemaphobia by Gough (1954), the phenomenon of mathematics anxiety is " $a$ feeling of tension and anxiety that interferes with the manipulation of numbers and the solving of the mathematical problems in a wide variety of ordinary life and academic situations" (Richardson \& Suinn, 1972, p. 551). Several studies have revealed that children, youth, and adults can experience mathematics anxiety, which may lead to the disruption of their mathematical learning and performance, both by causing avoidance of mathematical activities and by overloading and disrupting working memory during mathematical tasks (Dowker, Sarkar \& Looi, 2016). Females tend to rate themselves lower and to express more anxiety about mathematics (Else-Quest et al., 2010; Devine et al., 2012). In our study, $69.06 \%$ of participants identified as female. It is plausible that our gender-skewed sample was more prone to mathematics anxiety. Furthermore, several studies have suggested that ethnic minority students express more positive attitudes toward mathematics than White students from the USA (Catsambis, 1994). Eightysix percent of our sample identified as White/European American, which might be behind a possible presence of mathematics anxiety in our sample. Given the nature of the relationship between emotions and argument evaluation skills in our study, however, participants who experienced negative emotions during evidence 
evaluation demonstrated more sophisticated argument evaluation skills. This observation indicates that while mathematics anxiety deserves consideration, negative emotions did not seem to hinder performance, as one would expect if mathematics anxiety were occurring. Thus, we turn to considering the relationship between cognitive control and emotion.

We consider the possibility that emotions can affect goal pursuits and cognitive control. According to Chiew and Braver (2011), most of the goals pursued in daily life are emotionally or motivationally meaningful. Fredrickson (2004) suggested that positive emotions might be an adaptive signal indicating safety and security in the environment, thus giving freedom to explore and engage in new opportunities. A study conducted by Isen and Daubman (1984), showed that induction of positive emotions facilitated creative problem-solving (Isen et al., 1987). Scientific argumentation, specifically the task of coordinating a data set with a claim, also requires creative thought (Glassner \& Schwarz, 2007). Our study contradicts this trend; positive emotions experienced during evidence evaluation of the anti-conservation claim gave rise to lower levels of scientific argumentation skills. So rather than inhibiting creative thought, negative emotions experienced during evidence-evaluation may have honed argumentation skills, such that participants were more motivated to build a solid argument that resolved their negative emotions elicited by the anticonservation claim.

\section{Conservation Concern and Scientific Argumentation}

In our study, when students were asked to use the data to analyze the anti-conservation claim, students who demonstrated the most sophisticated argument evaluation skills had either very low or very high concern about conservation. This finding indicates that argument evaluation skills may be ramped up when students feel strongly, either positive or negatively, about a topic. In the context of thisstudy, strong positive feelings corresponded to viewing biodiversity conservation as highly important, and strong negative feelings corresponded to viewing it as not at all important. In other words, one's concern about conservation, if extreme, seemed to compel motivated reasoning (Kunda, 1990) when evaluating claims about conservation decisions. While this conclusion is made with caution, due to the marginal significance, we feel it is nevertheless important to report due to the damaging ramifications of a Type II error in this context; there are potential harmful effects of motivated reasoning when makingsuchimportantdecisions. Wefeel that thispotential relationship should be explored further and suggest a more robust measure of conservation concern be used, which to our knowledge does not yet exist. Nonetheless, a broader measure of environmental concern, such as the New Ecological Paradigm scale (Dunlap et al., 2000), could be used as a proxy or adapted to specifically measure concern for biodiversity conservation.

\section{Analyzing Pro-Conservation Claims}

When students used data as evidence to analyze a pro-conservation claim, none of the variables explored in this study (nature relatedness, conservation concern, emotions experienced during evidence evaluation) significantly influenced participants' ability to evaluate the claim. When trying to understand these findings, human attitudes towards conservation of species should be taken into account. As explored earlier, several studies have found that humans portray stronger attitudes in conserving species that are similar to humans (Colléony et al, 2017). A study conducted by Tisdell et al. (2006) supports this finding, which showed that respondents appeared to favor the survival of mammals rather than birds or reptiles. In our questionnaire, data for the proconservation scenario was based on aquatic bird species accompanied by an image of an aquatic bird, while data for the anti-conservation claim was based upon primates and carnivores, accompanied by an image of a primate. Thus, it is plausible that the participants may have experienced stronger emotions when evaluating the anticonservation claim, given that primates and carnivores were highlighted, while their emotions might not have been as strong when evaluating the pro-conservation scenario highlighting bird species. Our experimental design might have created an emotional bias in the anticonservation scenario. In the future, this can be resolved by using evidence solely focused on one group of species, so that the bias for mammals can be controlled.

\section{CONCLUSIONS}

The predictions for this study were that participants with a strong relationship with nature or high concern for conservation would exhibit high quality argument evaluation skills as they evaluate an anti-conservation argument, while participants with a weak relationship to nature or low concern for conservation will exhibit high quality evaluation skills as they evaluate a pro-conservation argument. We also predicted that participants who experience positive emotions during evidence evaluation will demonstrate higher quality argument evaluation skills, compared to participants who experience negative emotions during evidence evaluation. However, data analysis refuted both predictions. No statistically significant relationship was observed between nature relatedness and argumentation skills 
in either scenario, and participants who demonstrated higher levels of scientific argumentation experienced more negative emotions. Further, participants who demonstrated higher levels of scientific argumentation had extreme conservation concern (i.e., low or high). Thus, we conclude that emotions experienced during argument evaluation are important regarding evaluating anticonservation claims, but further research should focus on elucidating the mechanism through which emotions act. Further, we cautiously conclude that motivated reasoning may be at play when evaluating anti-conservation claims, due to participants' strong feelings about conservation's importance.

This study provides insight into how nature relatedness, conservation concern, and emotion influence scientific argumentation related to biodiversity conservation. It contributes to facilitating perceptions of nature-related scientific issues in more critical and sophisticated ways, allowing deeper insights to how reasoning about environmental problems can be taught in classrooms to improve scientific argumentation skills. This also allows better understanding of socio-scientific issues among students and general public which deems to be of importance as discussed earlier in the literature review.

\section{RECOMMENDATIONS}

Continued study is needed of students' evaluation of anti-conservation claims. Previous research indicates that negative emotion can inhibit problem-solving, but our study seems to indicate that slightly negative emotions, likely in response to hearing an anti-conservation claim, motivated participants to better build a robust rebuttal using evidence. As environmental educators wanting to help students build the skills necessary to make strong evidence-based claims and evaluate others' claims with evidence, we need to find this "sweet spot" in harnessing emotion to achieve learning goals, such that students are emotionally invested enough to deeply engage in scientific argumentation but not overwhelmed by negative emotions elicited by anti-conservation claims. Future research could accomplish this objective through a deeper exploration of students' abilities to evaluate data across all types of data (i.e., empirical, anecdotal, research findings presented in prose) to better elucidate the origin of negative emotions experienced during evidence evaluation (i.e., anxiety of interpreting empirical data versus negative emotions prompted by hearing an anti-conservation claim).

\section{LIMITATIONS}

Generalization of this study may be limited to broad groups of students, due to the demographics of the sample in which the majority of the participants were U.S. college students who identified as mostly White/European American, female, and from suburban communities. Thus, findings may not apply to other racial, ethnic, cultural, and international populations. Future studies should be conducted using a more representative national sample or an international sample, which will allow more useful comparisons and generalizations. This study was also restricted to undergraduate students majoring mostly in education or social sciences. These students' level of scientific argumentation may not be representative of other majors or that of graduate students, who are readily involved in research. Thus, a study comprising both undergraduate and graduate students would enable deeper comparisons across levels of scientific argumentation skill sets. Finally, limitations to our experimental design call for replication of this study with a more robust measure of conservation concern and argument-evaluation scenarios that make use of data describing consistently charismatic taxonomic groups.

\section{REFERENCES}

Albarracin, D., \& Kumkale, G. T. (2003). Affect as information in persuasion: A model of affect identification and discounting. Journal of Personality and Social Psychology, 84(3), 453-469. doi:10.1037/0022-3514.84.3.453

Allchin, D. (2012). Teaching the nature of science through scientific errors. Science Education, 96(5), 904-926. doi:10.1002/ sce. 21019

Asterhan, C. S. C., \& Schwarz, B. B. (2009). Argumentation and explanation in conceptual change: Indications from protocol analyses of peer-to-peer dialog. Cognitive Science, 33(3), 374-400. doi:10.1111/j.1551-6709.2009.01017.x

Bart, J., Platte, R., Andres, B., Brown, S., Johnson, J., \& Larned, W. (2013). Importance of the national petroleum reserve-Alaska for aquatic birds. Conservation Biology, 27(6), 1304-1312. doi:10.1111/cobi.12133

Batt, S. (2009). Human attitudes towards animals in relation to species similarity to humans: A multivariate approach. Bioscience Horizons: The International Journal of Student Research, 2(2), 180-190. doi:10.1093/biohorizons/hzp021

Catsambis, S. (1994). The path to math: Gender and racialethnic differences in mathematics participation from middle school to high school. Sociology of Education, 67, 199-215. doi:10.2307/2112791

Chi M. T. H. (2008). Three types of conceptual change: Belief revision, mental model transformation, and categorical shift. In S. Vosniadou (Ed.), Handbook of Research on Conceptual Change. Hillsdale, NJ: Erlbaum.

Chiew, K. S., \& Braver, T. S. (2011). Positive affect versus reward: emotional and motivational influences on cognitive control. Frontiers in Psychology, 2, 279. doi:10.3389/ fpsyg.2011.00279

Colléony, A., Clayton, S., Denis, C., Saint Jalme, M., \& Prevot, A. (2017). Human preferences for species conservation: Animal charisma trumps endangered status. Biological Conservation, 206, 263-269. doi:10.1016/j.biocon.2016.11.035 
Czech, B., Krausman, P. R., \& Borkhataria, R. (1998). Social construction, political power, and the allocation of benefits to endangered species. Conservation Biology, 12, 1103-1112. doi:10.1046/j.1523-1739.1998.97253.x

DeKay, M. L., \& McClelland, G. H. (1996). Probability and utility of endangered species preservation programs. Journal of Experimental Psychology: Applied, 2(1), 60-83. doi:10.1037/1076-898x.2.1.60

Devine A., Fawcett K., Szucs D., Dowker A. (2012). Gender differences in mathematics anxiety and the relation to mathematics performance while controlling for test anxiety. Behav. Brain Funct., 8, 1-9. doi:10.1186/1744-90818-33

Dowker, A., Sarkar, A., \& Looi, C. Y. (2016). Mathematics Anxiety: What Have We Learned in 60 Years?. Frontiers in psychology, 7, 508. doi:10.3389/fpsyg.2016.00508

Driver, R., Newton., P., \& Osborne, J. (2000). Establishing the norms of scientific argumentation in classrooms. Science Education, 84(3), 287. https://doi.org/10.1002/(SICI)1098237X(200005)84:3<287::AID-SCE1>3.0.CO;2-A

Dunlap, R., Liere, K. D., Mertig, A., \& Jones, R. (2000). Measuring endorsement of the new ecological paradigm: A revised NEP scale. Journal of Social Issues, 56, 425-442. doi:10.1111/00224537.00176

Duschl, R. A., \& Osborne, J. (2002). Supporting and promoting argumentation discourse in science education. Studies in Science Education, 38(1), 39-72. doi:10.1080/03057260208560187

Duschl, R. A., Schweingruber, H. A., \& Shouse, A.W. (2007). Taking science to school: Learning and teaching science in grades K-8.Washington, DC: National Academy Press.

Else-Quest, N., Hyde, J. S., \& Linn, M. (2010). Cross-national patterns of gender differences in mathematics: A metaanalysis. Psychological Bulletin, 136, 103-127. doi:10.1037/ a0018851

Fredrickson, B. L. (2004). The broadenand-build theory of positive emotions. Philos. Trans. R. Soc. Lond. B Biol. Sci., 359, 1367-1378. doi:10.4135/9781412956253.n75

Garcia-Marques, T., \& Loureiro, F. (2016). Dispositional beliefs regarding "affect as information" determine the perception of persuasive self-efficacy. Analise Psicologica, 34(1), 73-86. doi:10.14417/ap.1098

Glassner, A., \& Schwarz, B. (2007). What stands and develops between creative and critical thinking? Argumentation?. Thinking Skills and Creativity, 2(1), 10-18. doi:10.1016/j. tsc. 2006.10.001

Gough, M. F. (1954). Mathemaphobia: Causes and treatments. The Clearing House: A Journal of Educational Strategies, Issues and Ideas, 28(5), 290-294. doi:10.1080/00098655.19 54.11476830

Harrington, L. (2015). International commercial trade in live carnivores and primates 2006-2012: Response to Bush et al. 2014. Conservation Biology, 29(1), 293-296. doi:10.1111/ cobi.12448

Isen, A. M., \& Daubman, K. A. (1984). The influence of affect on categorization. Journal of Personality and Social Psychology, 47, 1206-1217. doi:10.1037/0022-3514.47.6.1206

Isen, A. M., Daubman, K. A., \& Nowicki, G. P. (1987). Positive affect facilitates creative problem solving. Journal of Personality and Social Psychology, 52, 1122-1131. doi:10.1037/00223514.52.6.1122

Kaplan, S. (2000). Human Nature and Environmentally Responsible Behavior. Journal of Social Issues, 56(3), 491-
508. doi:10.1111/0022-4537.00180

Kellert, S. R. (1978). Policy implications of a national study of American attitudes and behavioral relations to animals. U.S. Department of the Interior, Stock Number 024-101-00482-7, U.S., Government Printing Office, Washington DC.

Kunda, Z. (1987). Motivation and inference: Self-serving generation and evaluation of evidence. Journal of Personality and Social Psychology, 53, 636-647. doi:10.1037/00223514.53.4.636

Kunda, Z. (1990). The case for motivated reasoning. Psychological Bulletin, 108(3), 480-98. doi:10.1037/0033-2909.108.3.480

Lee, Y. C. (2007). Developing decision-making skills for socioscientific issues. Journal of Biological Education, 41, 170-177. doi:10.1080/00219266.2007.9656093

Lee, H. S., Liu, O. L., Pallant, A., Roohr, K. C., Pryputniewicz, S., \& Buck, Z. E. (2014). Assessment of uncertainty-infused scientific argumentation. Journal of Research in Science Teaching, 51(5), 581-605. doi:10.1002/tea.21147

Mauss, I. B., \& Robinson, M. D. (2009). Measures of emotion: A review. Cogntive Emotion, 23(2), 209-237. doi: 10.1080/02699930802204677.

Millar, R. \& Osborne, J. (Eds.). (1998). Beyond 2000: Science education for the future. London: King's College.

Nisbet, E. K., \& Zelenski, J. M. (2013). The NR-6: A new brief measure of nature relatedness. Frontiers in Psychology, 4(NOV), 1-11. doi:10.3389/fpsyg.2013.00813

Nisbet, E. K., Zelenski, J. M., \& Murphy, S. A. (2009). With nature to environmental concern and behavior. Environment and Behavior, 41(5), 715-740. doi:10.1177/0013916508318748

Presley, M., Sickel, A., Muslu, N., Merle-Johnson, D., Witzig, S., Izci, K., \& Sadler, T. (2013). A framework for socio-scientific issues based education. Science Educator. 22. 26-32.

Richardson, F. C., \& Suinn, R. M. (1972). The mathematics anxiety rating scale: Psychometric data. Journal of Counseling Psychology, 19, 551-554. doi:10.1037/h0033456

Tam, K. P. (2013). Concepts and measures related to connection to nature: Similarities and differences. Journal of Environmental Psychology, 34, 64-78. doi:10.1016/j.jenvp.2013.01.004

Tisdell, C.,Wilson, C., Nantha, H.S. (2006). Public choice of species for the 'Ark': Phylogenetic similarity and preferred wildlife species for survival. Journal for Nature Conservation, 14(2), 97-105. doi:10.1016/j.jnc.2005.11.001

Toulmin, S. (1958). The uses of argument. Cambridge: Cambridge University Press.

Villata, S., Cabrio, E., Jraidi, I., Benlamine, M., Chaouachi, M., Frasson, C., \& Gandon, F. (2017). Emotions and personality traits in argumentation: An empirical evaluation. Argument \& Computation, 8, 1-27. doi:10.3233/aac-170015

Wang, H., Hong, Z., Lin, H., \& Tsai, C. (2020). The relationships among adult sustainability attitudes, psychological well-being, nature relatedness, and interest in scientific issues. Current Psychology, doi:10.1007/s12144-020-00708-1

Wyer, R. S., \& Dieter, F. (1983). The effects of feedback about self and others on the recall and judgments of feedback-relevant information. Journal of Experimental Social Psychology, 19(6), 540-59. doi:10.1016/0022-1031(83)90015-x 


\section{SUPPLEMENT A: SURVEY}

Survey questionnaire that which was distributed among the participants

Nature Relatedness and Scientific Argumentation

1. General Question on species conservation

How important do you think it is to protect each of the following groups of organisms from extinction?

Primates, Carnivores, Birds

Answer choices: 5: Extremely important - Not at all important

2. This section of the questionnaire will present you with two scenarios. In each scenario, you are given some data in a table and a person's conclusion based on the data in the table. Questions that follow will ask you about the data and the person's conclusion. The data are purposefully ambiguous and thus there is no single correct conclusion to be drawn from them. Please attempt to be thorough when explaining your thoughts and opinions.

The data below show carnivores and primates that were frequently traded as live animals for personal (e.g. as pets) or commercial purposes (e.g. fur farming) for the years 2006-2012.

\begin{tabular}{lllll}
\hline $\begin{array}{l}\text { Common Name } \\
\text { Asian short-clawed }\end{array}$ & $\begin{array}{l}\text { \# of Animals Traded } \\
\text { Personal Purposes }\end{array}$ & Commercial Purposes & $\begin{array}{l}\text { \% of Wild Population } \\
\text { that was Traded }\end{array}$ & $\begin{array}{l}\text { \# of Animals Taken from } \\
\text { the Wild per Year }\end{array}$ \\
$\begin{array}{l}\text { otters, African clawless } \\
\text { otters }\end{array}$ & 01 & 123 & $2 \%$ & $0-2$ \\
$\begin{array}{l}\text { Marmosets } \\
\text { Capuchins }\end{array}$ & 14 & 1612 & $2 \%$ & $0-32$ \\
$\begin{array}{l}\text { Pampas foxes } \\
\text { Lion, tiger, leopard, }\end{array}$ & 05 & 893 & $97 \%$ & $17-183$ \\
jaguar & 107 & 501 & $100 \%$ & $0-500$ \\
Kinkajou & 01 & 127 & $10 \%$ & $2-10$ \\
$\begin{array}{l}\text { Tamarins } \\
\text { Squirrel monkeys }\end{array}$ & 01 & 599 & $98 \%$ & $40-109$ \\
$\begin{array}{l}\text { Fennec foxes } \\
\text { Black bear, brown bear, }\end{array}$ & 07 & 360 & $90 \%$ & $14-107$ \\
$\begin{array}{l}\text { Asiatic bear } \\
\text { Serval }\end{array}$ & 20 & 804 & $94 \%$ & $200-727$ \\
\hline
\end{tabular}

Data from Harrington (2015). International commercial trade in live carnivores and primates 2006-2012: Response to Bush et al. 2014. Conservation Biology, 29, 293-296).

Based on these data, Jordan concludes that the trade of live carnivores and primates does not have a substantial effect on the wild populations of these animals. Please share what you think about Jordan's conclusion in the questions below.

\section{Scenario 1}

a. Indicate the extent to which Jordan's conclusion makes you experience the following emotions:

Angry, sad, frustrated, happy, satisfied, pleased

Answer choices: from 0 - 10: Not at all (5), Very much (5)

b. To what extent do you agree with Jordan's conclusion, that the trade of live carnivores and primates does not have a substantial effect on the wild populations of these animals?

Answer choices: 4: Strongly agree - Strongly disagree 
(i) If the participant chooses answer options strongly agree or somewhat agree they would be directed to the following question.

Please choose the option that best fits why you agree with Jordan's conclusion that the trade of live carnivores and primates does not have a substantial effect on the wild populations of these animals. (The table with data was reincluded here for the convenience of the participant).

Answer options: 4:

These animals are not important to me.

Jordan's conclusion makes sense to me.

I agree because for the most part, only a small number are taken from the wild each year, judging from the number of animals taken per year.

I agree because in several cases, only a small percentage of the population is taken. For example, only $10 \%$ of the large cats (lion, tiger, leopard, jaguar) wild population was taken, which means that $90 \%$ of the population remains to reproduce and maintain the population.

(ii) If the participant chooses answer options somewhat disagree or strongly disagree they would be directed to the following question.

Please choose the option that best fits why you disagree with Jordan's conclusion that the trade of live carnivores and primates does not have a substantial effect on the wild populations of these animals. (The table with data was reincluded here for the ease of the participant).

Answer options: 4:

I disagree because for most of the animals, a percentage higher than $80 \%$ was traded which is a big percentage.

I disagree because for most of the animals a high percentage of the wild population is traded and if this continues these species will become extinct in the wild.

Jordan is wrong.

I love these animals.

(i) If the participant strongly agreed or somewhat agreed they would be directed to the following question.

Under what conditions if any, might Jordan's conclusion be incorrect? If you believe there is no possible way Jordan's conclusion could be inaccurate, please just state, "none."

(ii) If the participant somewhat disagreed or strongly disagreed they would be directed to the following question.

Under what conditions if any, might Jordan's conclusion be correct? If you believe there is no possible way Jordan's conclusion could be accurate, please just state, "none.

\section{Scenario 2}

The data below show density and abundance of aquatic birds in three regions in Alaska: 1 . The National Petroleum Reserve (an area of land on the Alaska North Slope), 2. The Arctic Refuge (a national wildlife refuge in northeastern Alaska), 3. Prudhoe Bay (located in North Slope Borough in Alaska) (Data from Bart, Platte, Andres, Brown, Johnson, \& Larned (2013)). Importance of the National Petroleum Reserve-Alaska for Aquatic Birds. Conservation Biology, 27: 1304-1312).

Based on these data, Jaime concludes that the National Petroleum Reserve should not be subjected to drilling for oil, because it serves as critical habitat for a majority of aquatic bird populations. Please share what you think about Jaime's conclusion in the questions below.

a. Indicate the extent to which Jaime's conclusion makes you experience the following emotions:

Angry, sad, frustrated, happy, satisfied, pleased

Answer choices: from 0 - 10: Not at all (5), Very much (5) 


\begin{tabular}{|c|c|c|c|c|}
\hline Parameter & Region & $\begin{array}{l}\text { Waterfowl, loons, } \\
\text { grebes }\end{array}$ & Shorebirds & Gulls, terns, jaegers \\
\hline \multirow{3}{*}{ Density (birds per square kilometer) } & $\begin{array}{l}\text { National Petroleum } \\
\text { Reserve }\end{array}$ & 22 & 151 & 6 \\
\hline & Arctic Refuge & 10 & 38 & 2 \\
\hline & Prudhoe Bay & 29 & 81 & 6 \\
\hline \multirow{3}{*}{ Population size } & $\begin{array}{l}\text { National Petroleum } \\
\text { Reserve }\end{array}$ & 667,805 & $4,540,047$ & 186,579 \\
\hline & Arctic Refuge & 78,555 & 307,611 & 17,708 \\
\hline & Prudhoe Bay & 516,030 & $1,431,007$ & 100,233 \\
\hline \multirow{3}{*}{$\%$ of Total Population } & $\begin{array}{l}\text { National Petroleum } \\
\text { Reserve }\end{array}$ & $53 \%$ & $72 \%$ & $61 \%$ \\
\hline & Arctic Refuge & $6 \%$ & $5 \%$ & $6 \%$ \\
\hline & Prudhoe Bay & $41 \%$ & $23 \%$ & $33 \%$ \\
\hline
\end{tabular}

b. To what extent do you agree with Jaime's conclusion, that the National Petroleum Reserve should not be subjected to drilling for oil, because it serves as critical habitat for a majority of aquatic bird populations?

Answer choices: 4: Strongly agree - Strongly disagree

(i) If the participant chooses answer options strongly agree or somewhat agree they would be directed to the following question.

Please choose the option that best fits why you agree with Jaime's conclusion, that the National Petroleum Reserve should not be subjected to drilling for oil, because it serves as critical habitat for a majority of aquatic bird populations. (The table with data will be reincluded here for the convenience of the participant).

Answer options: 4 :

I agree because from the data given, it is evident that the number of aquatic bird populations in the National Petroleum Reserve is high. This means that the National Petroleum Reserve is important habitat.

I agree because the population size for all birds is highest in the National Petroleum Reserve.

These birds are beautiful.

Jaime's conclusion just makes sense to me.

(ii) If the participant chooses answer options somewhat disagree or strongly disagree they would be directed to the following question.

Please chose the option that best fits why you disagree with Jaime's conclusion that the National Petroleum Reserve should not be subjected to drilling for oil, because it serves as critical habitat for a majority of aquatic bird populations. (The table with data will be reincluded here for the convenience of the participant).

Answer options: 4 :

I am not interested in aquatic birds.

I disagree because according to the data, the density of waterfowl, loons, and grebes higher in Prudhoe Bay than in the National Petroleum Reserve. Thus, Prudhoe Bay is more important as a habitat.

I disagree because I think Jaime is wrong.

I disagree because the density of waterfowl, loons and grebes is higher in Prudhoe Bay.

(i) If the participant chooses answer options strongly agree or somewhat agree they would be directed to the following question. 
Under what conditions might Jaime's conclusion be incorrect? If you believe there is no possible way Jaime's conclusion could be inaccurate, please just state, "none."

(ii) If the participant somewhat disagreed or strongly disagreed they would be directed to the following question. Under what conditions might Jaime's conclusion be correct? If you believe there is no possible way Jaime's conclusion could be accurate, please just state, "none."

\section{Relationship with Nature}

For the following questions, please indicate the extent to which you agree or disagree with the statements. Please respond as you really feel, rather than how you think most people feel or how you think you should feel.

Answer choices for each question: 5: Strongly agree - Strongly disagree

a. My ideal vacation spot would be a remote, wilderness area.

b. I always think about how my actions affect the environment.

c. My connection to nature and the environment is a part of my spirituality.

d. I take notice of wildlife wherever I am.

e. My relationship to nature is an important part of who I am.

f. I feel very connected to all living things and the earth.

4. Demographic Questions

a. What discipline do you most identify with?

Answer choices: Fine Arts, Humanities, Social Sciences, Business, Natural Sciences, Education

b. What is your year of birth?

c. Choose one or more races that you consider yourself to be:

Answer choices: White, Black or African American, American Indian or Alaska Native, Asian, Native Hawaiian or Pacific Islander, Other

d. Are you Spanish, Hispanic, or Latino or none of these?

Answer choices: Yes, None of these

e. What sex do you identify with?

Answer choices: Male, Female, Non-binary, Prefer not to say

f. Which of the following best describes your hometown?

Answer choices: Urban, Suburban, Rural

g. Did you vote in the last election?

Answer choices: Yes, No

If you expect to receive extra credit for participation in this research study, please follow this link to provide information that will be provided to your instructor, so you can receive the credit. Your survey anonymity will be maintained. 


\section{SUPPLEMENT B: DEMOGRAPHICS}

Demographic characteristics of the survey questionnaire participants.

\begin{tabular}{|c|c|c|}
\hline Demographic characteristic & & Percentage \\
\hline \multirow[t]{6}{*}{ Major } & Natural Sciences & 14.83 \\
\hline & Social Sciences & 22.18 \\
\hline & Business & 23.3 \\
\hline & Fine Arts & 9.32 \\
\hline & Education & 23.72 \\
\hline & Humanities & 9.32 \\
\hline \multirow[t]{5}{*}{ Year in school } & 1 st & 67.79 \\
\hline & 2nd & 13.13 \\
\hline & $3 r d$ & 11.01 \\
\hline & 4th & 8.89 \\
\hline & 5th & 2.11 \\
\hline \multirow[t]{8}{*}{ Race/Ethnicity } & White or European American & 86 \\
\hline & East Asian or Asian American & 2.11 \\
\hline & American Indian, Native American, Native Alaskan, or First Peoples & 0.42 \\
\hline & Not important & 0.42 \\
\hline & African American or Black & 7.18 \\
\hline & Middle Eastern or Arab American & 0.42 \\
\hline & Latina American, Latina, Hispanic & 2.94 \\
\hline & CODA & 0.42 \\
\hline \multirow[t]{2}{*}{ Spanish/Hispanic/Latino } & Yes & 9.74 \\
\hline & No & 90.25 \\
\hline \multirow[t]{3}{*}{ Gender } & Male & 30.5 \\
\hline & Female & 69.06 \\
\hline & Nonbinary & 0.42 \\
\hline \multirow[t]{3}{*}{ Hometown } & Urban & 13.13 \\
\hline & Sub urban & 59.74 \\
\hline & Rural & 27.11 \\
\hline \multirow[t]{2}{*}{ Vote } & Yes & 40.25 \\
\hline & No & 59.74 \\
\hline
\end{tabular}

